\title{
PIGMENTOS FOTOSSINTETIZANTES, AMINOÁCIDOS E PROTEÍNAS EM PLANTAS JOVENS DE GRAVIOLA SUBMETIDA AO DÉFICIT HÍDRICO
}

\author{
Lillian Matias de Oliveira ${ }^{1}$; Jaomara Nascimento da Silva ${ }^{1}$; Carla Carolynne Resueno \\ Coelho $^{1}$; Myriam Galvão Neves'; Raimundo Thiago Lima da Silva²; Cândido Ferreira \\ de Oliveira Neto ${ }^{3}$. \\ ${ }^{1}$ Graduanda do curso de Agronomia da Universidade Federal Rural da Amazônia (UFRA). Capitão Poço, Pará, \\ Brasil. lillianoliveira4@ hotmail.com \\ 2 Professor, Mestre da UFRA. Capitão Poço, Pará, Brasil. thiagoufra@ hotmail.com \\ ${ }^{3}$ Professor, Doutor da UFRA. Capitão Poço, Pará, Brasil. candido.neto@ufra.edu.br.
}

RESUMO: A gravioleira é uma planta de clima tropical, sendo cultivada nas regiões Norte, Nordeste, Centro-Oeste e Sudeste do Brasil. A suspensão hídrica ocasiona mudanças nos processos bioquímicos da planta. Este trabalho tem por objetivo verificar o efeito do estresse hídrico nos teores dos pigmentos fotossintéticos, nas concentrações de aminoácidos livres totais e proteínas solúveis totais em plantas jovens de graviola. O experimento foi realizado em casa de vegetação da Universidade Federal Rural da Amazônia - UFRA, Campus Capitão Poço-PA. Sendo utilizadas plantas jovens de graviola que foram submetidas a dois regimes hídricos: irrigado (controle) e déficit hídrico, o delineamento experimental utilizado foi inteiramente casualizado com 15 repetições, totalizando 30 unidades experimentais. Os resultados foram aplicados a análise de variância e comparadas às médias pelo teste de Tukey ao nível de $5 \%$ de significância. Os teores dos pigmentos fotossintetizantes foram reduzidos nas plantas que foram submetidas ao déficit hídrico quando comparadas ao controle, as concentrações de aminoácidos aumentaram em plantas com estresse e as concentrações de proteínas diminuíram em plantas de graviola submetidas ao déficit hídrico quando estas foram comparadas com as plantas controle.

PALAVRAS-CHAVE: clima tropical, concentrações, processos bioquímicos.

\section{PHOTOSYNTHETIC PIGMENTS, AMINO ACID AND PROTEIN IN PLANTS YOUNG GRAVIOLA SUBMITTED TO WATER DEFICIT}

\begin{abstract}
The soursop is a tropical climate plant and is cultivated in the North, Northeast, Midwest and Southeast of Brazil. The suspension fluid causes changes in the biochemical processes of the plant. This study aims to determine the effect of water stress on the content of photosynthetic pigments in the concentrations of free amino acids and soluble proteins in young plants of soursop. The experiment was conducted in a greenhouse at the Federal Rural University of Amazonia - UFRA, Campus Capitão Poço-PA. Being used soursop seedlings were subjected to two water regimes: irrigated (control) and drought, the experimental design was completely randomized with 15 replications, totaling 30 experimental units. The results were applied to analysis of variance and the averages compared by Tukey test at 5\% significance level. The content of photosynthetic pigments were reduced in plants that were subjected to water deficit when compared to the control, concentrations of amino acids in plants with increased stress and protein concentrations decreased in soursop plants subjected to water deficit when they were compared with plants control.
\end{abstract}

KEY-WORDS: biochemical processes, concentrations, tropical climate. 


\section{INTRODUÇÃO}

A gravioleira (Annona muricata L.) apresenta-se como uma das espécies de grande importância econômica para a fruticultura regional. A demanda pelos frutos cada vez mais crescente é atribuída às suas qualidades organolépticas, que possibilitam a sua utilização tanto para consumo "in natura" quanto para aproveitamento pela agroindústria (VIÉGAS; FRAZÃO, 2004).

O conhecimento das necessidades hídricas e nutricionais de máxima eficiência econômica para as culturas é indispensável para a obtenção de sucesso no empreendimento frutícola, pois a água e os nutrientes são os fatores que mais limitam o rendimento da planta (RUGGIERO et al., 1996).

Segundo Larcher (2006) o estresse é considerado um desvio significativo das condições ótimas para a vida, que induz a mudanças e respostas nos níveis funcionais dos organismos, as quais são reversíveis a princípio, podendo se tornar permanente.

O objetivo deste trabalho foi verificar o efeito do estresse hídrico nos teores dos pigmentos fotossintéticos, nas concentrações de aminoácidos livres totais e proteínas solúveis totais em plantas jovens de graviola.

\section{MATERIAL E MÉTODOS}

O experimento foi conduzido em casa de vegetação da Universidade Federal
Rural da Amazônia (UFRA), PA, Brasil. Foram utilizadas plantas jovens de graviola e colocadas por um mês em aclimatação.

$\mathrm{O}$ experimento foi realizado em janeiro de 2010, no qual as plantas foram submetidas a dois regimes hídricos: irrigado (controle) e déficit hídrico, e colocadas em déficit hídrico no período de 40 dias.

O delineamento experimental utilizado foi inteiramente casualizado com 15 repetições, totalizando 30 unidades experimentais, cada unidade experimental foi composta de uma (1) planta/vaso.

Foi aplicada a análise de variância nos resultados e comparadas às médias pelo teste de Tukey ao nível de $5 \%$ de significância, realizadas através do Sasinstitute (1996). As análises dos teores de clorofila $a, b$, total e carotenóides através da matéria fresca foram feitas pelo o método de Lichthenthaler (1987) e para a determinação das concentrações de proteínas e aminoácidos foi realizada através do método de Bradford (1976) e Peoples et al. (1989), respectivamente.

\section{RESULTADOS E DISCUSSÃO}

Os resultados mostraram que em plantas de graviola o período de suspensão hídrica foi suficiente para promover um decréscimo nos teores de clorofila $a, b$, total $(a+b)$ e carotenóides (Figura 1). Decréscimos nos teores de clorofila ou 
proteína podem, portanto, ser sintoma característico de estresse oxidativo, e tem sido verificado em plantas sob estresse hídrico (SMIRNOFF, 1995).

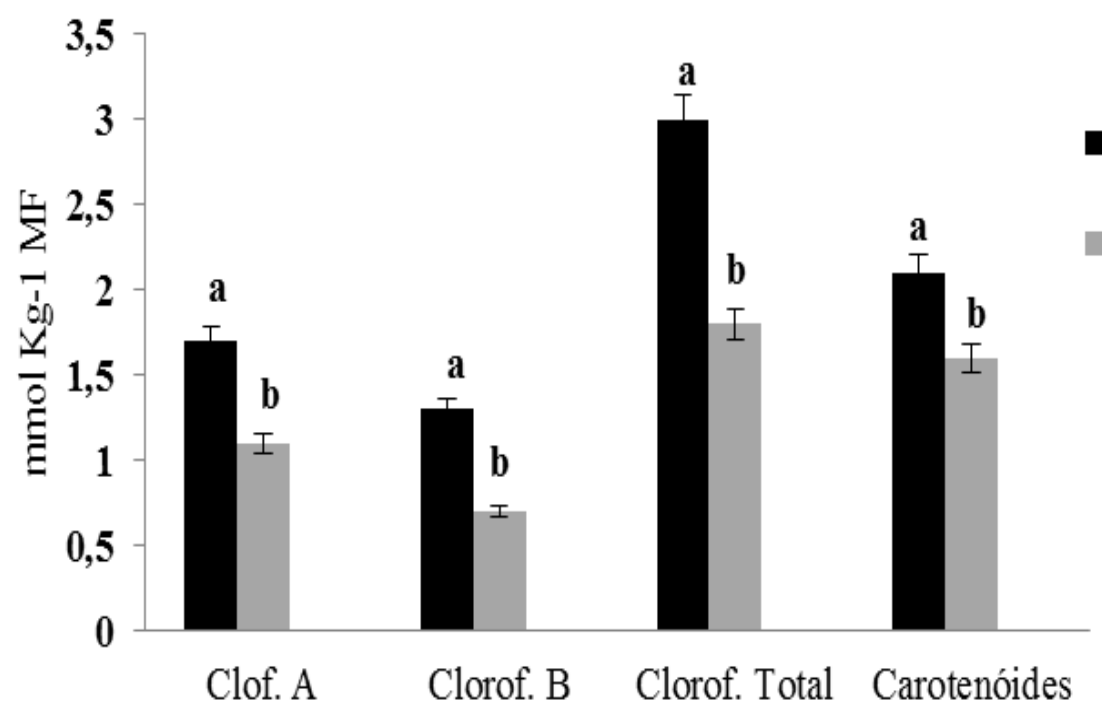

Figura 1. Teores de clorofila $a, b$, total $(a+b)$ e carotenóides em folhas de plantas jovens de graviola submetidas a suspensão hídrica. As letras diferentes mostram diferença estatística, comparadas pelo teste Tukey ao nível de 5\% de probabilidade. As barras representam os desvios padrões das médias.

Pode ser observado na Figura 2 que as concentrações de aminoácidos livres totais nas raízes e nas folhas das plantas submetidas ao estresse aumentaram quando comparados às plantas controle. $\mathrm{O}$ acúmulo de aminoácidos pode ser decorrente da restrição da síntese de proteínas, bem como os distúrbios pela deficiência hídrica nos tecidos do floema, reduzindo a translocação para outros órgãos (SUBBARAO et al., 2000).
Sendo assim, o acúmulo de aminoácidos pode ser considerado como um sinal de tolerância das plantas sob diferentes estresses ambientais (SZEGLETES et al., 2000).

Na figura 3 houve uma diminuição da concentração de proteínas solúveis totais nas raízes e folhas das plantas submetidas ao estresse hídrico quando comparadas ao controle. Este resultado está relacionado ao aumento da atividade de proteínas 
proteolíticas, que quebram as proteínas de bioquímico (YORDANOV et al., 2000; reservas das plantas e da diminuição XIONG et al., 2002).

síntese de proteínas, haja vista, que o déficit hídrico afeta todo o seu processo

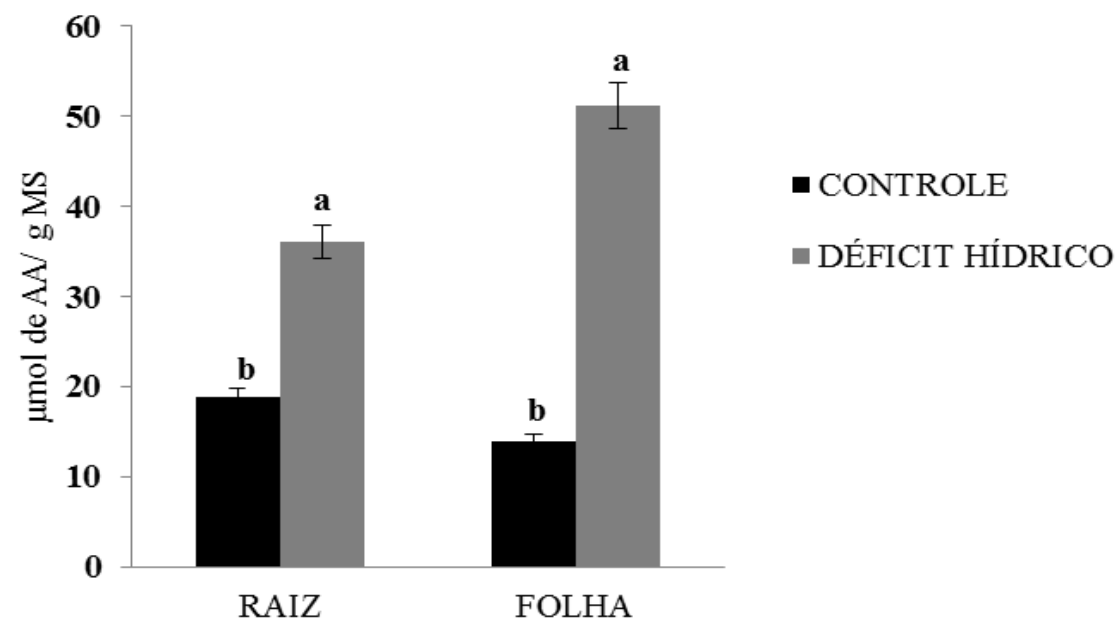

Figura 2. Concentrações de Aminoácidos livres totais em folhas e raiz de plantas jovens de graviola submetidas à suspensão hídrica. As letras diferentes mostram diferença estatística, comparadas pelo teste Tukey ao nível de 5\% de probabilidade. As barras representam os desvios padrões das médias.

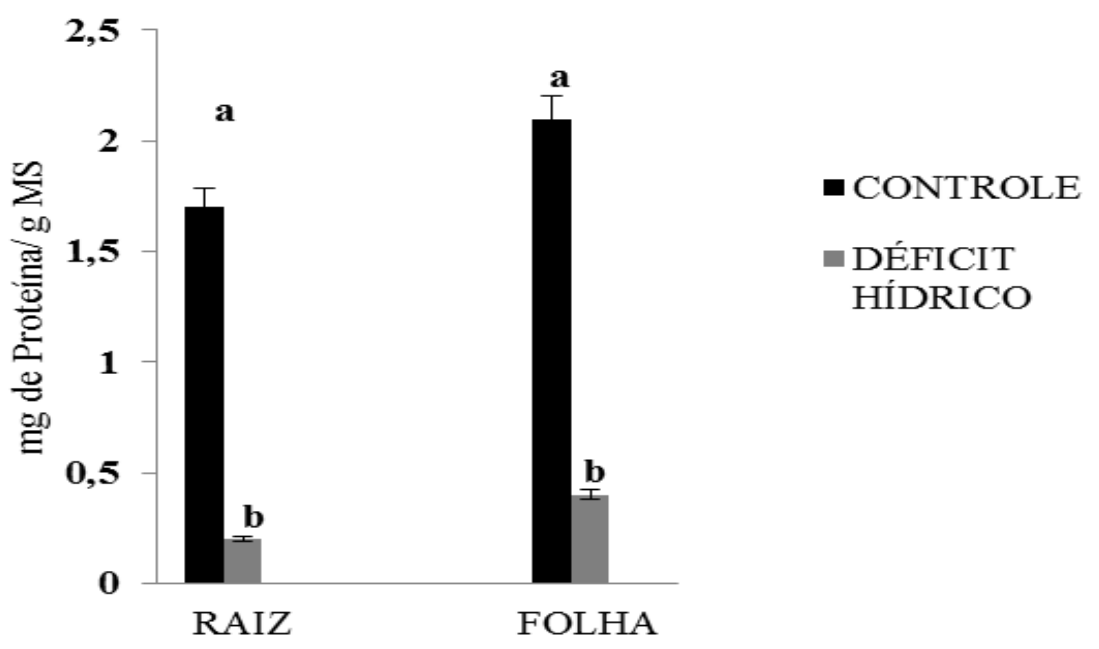

Figura 3. Concentrações de aminoácidos livres totais em folhas e raiz de plantas jovens de graviola submetidas a suspensão hídrica. As letras diferentes mostram diferença estatística, comparadas pelo teste Tukey ao nível de 5\% de probabilidade. As barras representam os desvios padrões das médias. 


\section{CONCLUSÕES}

Em condições de déficit hídrico as plantas de graviola sofrem redução nos teores de pigmentos fotossintéticos, redução na concentração de proteínas solúveis totais e um aumento significativo nas concentrações de aminoácidos livres totais.

\section{REFERÊNCIAS}

BRADFORD, M. M. A rapid and sensitive method for the quantitation of microgram quantities of protein utilizing the principle of protein-dye binding. Anal. Biochem. v. 72, p. 248-254, 1976.

\section{LARCHER, W. Ecofisiologia Vegetal .}

Tradução: Prado, C. H. B. A. São Carlos: Rima, 2006. 531 p.

LICHTHENTHALER, H. K. Chlorophylls and carotenoids: pigments of photosynthetic biomembranes. In: COLOWICK S.; KAPLAN, P. (ed) Methods in Enzimology, v.148. San Diego: Academic Press, 1987. p. 350-382.

PEOPLES, M. B.; FAIZAH, A. W.; REAKASEM, B.; HERRIDGE, D. F. Methods for evaluating nitrogen fixation by nodulated legumes in the field. Australian Centre for International Agricultural Research Canberra, 1989. 76 p.

RUGGIERO, C.; AZEVEDO, L. C.; GOMES, M. M. A.; SOUZA, M. A.
Maracujá para exportação: aspectos técnicos da produção. Brasília: EMBRAPA, 1996. 64 p. (Publicação técnica da FRUPEX, 19)

SAS INSTITUTE. SAS/STAT. User's Guid: version 6.12. Cary, NC: SAS Institute, 1996.

SMIRNOFF, N. Metabolic flexibility in relation to the environment. In: Environment and plant metabolism: flexibility and acclimation. Oxford: Bios Scientific publishers, 1995. p. 1-13.

SUBBARAO, G. V., NAM, N. H., CHAUHAN Y. S.; JOHANSEN, C. Osmotic adjustment, water relations and carbohydrate remobilization in pigeonpea under water stress. Journal of Plant Physiology, v. 157, p. 651-659, 2000.

SZEGLETES, Z., ERDEI, L., TARI, I.; CSEUZ, L. Accumulation of osmoprotectants in wheat cultivars of different drought tolerance. Cereal Research Communications, v. 28, p. 403410. 2000.

VIÉGAS, I. de J. M.; FRAZÃO, D. A. C. Graviola: Nutrição, calagem e adubação. Belém: Embrapa, 2004. (Circular técnica, 36).

XIONG, L.; SCHUMAKER, K. S.; ZHU, J-K. Cell Signaling during Cold, Drought, and Salt Stress. The Plant Cell, v. 14, p.165-183, 2002. 
YORDANOV, I.; VELIKOVA, V.;

TSONEV, T. Plant responses to drought,

acclimation and stress tolerance.

Photosynthetica, v. 38, n. 1, p. 171-186,

2000. 